\title{
DO VERDE ÀS CINZAS: ANÁLISE DAS NORMAS JURÍDICO-AMBIENTAIS QUE REGULAMENTAM A EXPLORAÇÃO DE MADEIRA DO BIOMA CERRADO PARA A PRODUÇÃO DE CARVÃO.
}

FROM THE GREEN TO THE ASHES: ANALYSIS OF THE JURIDICAL - ENVIRONMENTAL NORMS THAT REGULATE THE EXPLOITATION OF CERRADO WOODS FOR COAL PRODUCTION. ${ }^{1}$

\section{Bozzini, A. C. ${ }^{2}$}

1 Pesquisa subvencionada pela FAPESP concluída no ano de 1999.

2 Prof. Msc. Curso de Biologia FAFIG - Guaxupé/MG. Av. D. Floridiana, 463 - Centro. CP 204 CEP 37800-000. Guaxupé-MG.

\section{RESUMO}

O presente trabalho é uma pesquisa das normas jurídico-ambientais da exploração de madeira em Cerrado para produção de carvão vegetal. O local de estudo foi a região Noroeste do Estado de Minas Gerais onde a exploração do Cerrado é intensa por causa da produção de carvão vegetal utilizado nas siderúrgicas. Essa região é considerada a maior produtora e consumidora de carvão vegetal de matas nativas do Brasil.

Palavras - chave: Carvão; Cerrado; legislação ambiental; normas ambientais; direito ambiental.

\section{ABSTRACT}

The present work is a research of juridical-environmental norms of "Cerrado" wood exploitation for vegetable coal production. The place of study was the 
northwest region of Minas Gerais State - Brazil, where the exploitation of the "Cerrado" is very intense due to vegetable coal production used by siderurgic plants. This area is considered the largest producer and consumer of vegetable coal from brazilian natural forests.

KEYWORDS: Coal; Savannahs; Environmental Law; Environmental Norms; Cerrado.

\section{INTRODUÇÃO}

A utilização irracional dos biomas traz agressões ao meio ambiente $\mathrm{e}^{\mathbf{3}} \mathrm{e}$ conseqüências irreversíveis para as presentes e futuras gerações.

Entre os vários biomas atingidos por essa desordem está o Cerrado.

Há, claramente, interesses no Cerrado, entre os quais a utilização de sua madeira para a produção de carvão vegetal.

Dentre os entes federados brasileiros, o Estado de Minas Gerais tem destaque, já que produziu, em 1987, $21.466 .129 \mathrm{~m}^{3}$ de carvão, sendo que $25 \%$ foi de origem de reflorestamento e $74,5 \%$ de origem nativa, e do total de carvão vegetal produzido, pelo menos $60 \%$ era de origem nativa do Cerrado.

A região do Estado de Minas Gerais que mais produziu carvão vegetal nativo no ano de 1987 foi a do Noroeste (47,223\%), seguida do Triângulo e Alto Paranaíba $(18,584 \%)$. Esses dados demonstram que a produção de carvão nativo em nosso país está concentrada, em grande parte, nas áreas de ocorrência dos Cerrados (NETO, 1991).

Dados mais recentes, fornecidos pela ABRACAVE (1998), demonstram que a região Noroeste é ainda a que mais extrai lenha de Cerrado para a produção de carvão.

Observa-se ainda que dentre os principais Estados consumidores de carvão vegetal, Minas Gerais também se destaca em primeiro lugar, tendo utilizado, em 1988, $78,41 \%$ do total consumido no Brasil, seguido do Estado de São Paulo com 4,88\% (NETO, 1991). A dados semelhantes chegaram RESENDE (1986) e FERNANDES NETO (1993).

Em razão dessas informações objetivou-se este trabalho em analisar o papel do Estado, como mantenedor da ordem e do bem estar social, nas questões pertinentes às normas jurídico-ambientais que regulamentam a exploração de madeira em Cerrado para a produção do carvão na região do Noroeste, do Estado de Minas Gerais.

A metodologia desenvolvida é qualitativa, constando de três etapas: a) 
levantamento e análise bibliográfica em órgãos e entidades públicas e privadas; $b$ ) análise dos documentos e das normas jurídico-ambientais federais e do Estado de Minas Gerais; c) trabalho de campo na região Noroeste e entrevistas com responsáveis.

\section{O CERRADO: IMPORTÂNCIA AMBIENTAL E DEFINIÇÃO} FERRI (1980).

O Cerrado cobre uma área de 20 a $25 \%$ do território brasileiro, segundo

Há ocorrência de Cerrado em 16 unidades constituintes do Brasil: Amapá, Amazonas, Bahia, Distrito Federal, Goiás, Maranhão, Mato Grosso, Minas Gerais, Pará, Paraíba, Paraná, Pernambuco, Piauí, Rondônia, Roraima, São Paulo (FERRI, 1977).

Segundo Adámoli apud SILVA (1994), em razão da sua extensão e situação geográfica, os Cerrados apresentam grande variação de solos, clima, fauna e flora.

Autores, como CAVALCANTI (1996) e SANTILI (1997), destacam a biodiversidade do Cerrado em relação a outros biomas.

SILVA (1994) afirma que o Brasil possui cerca de 30\% das plantas e espécies animais que ocorrem no mundo, distribuídos em seus diferentes ecossistemas. Destaca esse autor que as pesquisas têm demonstrado que as espécies nativas dos Cerrados apresentam um elevado potencial para aproveitamento econômico, abrindo uma nova perspectiva para a racionalização da ocupação da região.

São várias as definições sobre Cerrado que se encontram disponíveis nas bibliografias. Segundo EMBRAPA apud FERRI (1977) e LOPES (1984), o Cerrado, em sentido genérico, é um grupo de formas de vegetação que se apresenta segundo um gradiente de biomassa. À forma de menor biomassa, que é o campo sujo de cerrado, seguem-se o campo cerrado, o cerrado e o cerradão.

Não há definição lato sensu de Cerrado na legislação federal brasileira.

A Portaria Normativa IBAMA 83, de setembro de 1991, define stricto sensu o cerradão, em seu art. $3^{0}, \S 1^{\underline{0}}$ : "a vegetação xeromórfica, de engalhamento profuso, provida de grandes folhas coriáceas, perenes em sua maioria e com casca corticosa não apresentando estrato arbustivo nítido, e o estrato graminoso é distribuído em tufos dispersos, entremeados de plantas lenhosas raquíticas"; e stricto sensu o cerrado, em seu art. $3^{\mathrm{O}}, \S 2^{\mathrm{O}}$ : "forma de vegetação xeromórfica com fisionomias diversas, de arbórealenhosa, com porte quase florestal, a gramíneo-lenhosa, onde se destacam as espécies de Angico-jacaré (Piptadenia sp), Aroeira (Astronium sp), Jacarandá (Machaerium sp), entre outras". 
Na legislação do Estado de São Paulo, no Decreto 49.141, de 28 de dezembro de 1967, em seus artigos $4^{0}$ e $5^{\circ}$, há também a definição de Cerrado e Cerradão stricto sensu. Importante observar que o Parágrafo único do art. $4^{\mathrm{O}}$ dessa norma exclui o Cerrado das Florestas. "Art. $4^{0}-$ Cerrado é a formação vegetal e constituída por dois andares: o primeiro de vegetação rasteira e o segundo de arbustos e formas arbóreas, que raramente ultrapassam 6 (seis) metros de altura, apresentando caules tortuosos, recobertos de espessas cascas, com folhas coreáceas e aparência de vegetação xeromorfa e havendo dominância do segundo andar". Para efeitos legais, os cerrados não são considerados florestas. "Art. $5^{\mathrm{O}}$ - Cerradão é a formação vegetal constituída de três andares distintos: o primeiro apresenta espécies rasteiras ou de pequeno porte, umbrófilas; o segundo, arbustos e pequenas formas arbóreas, constituindo sub-bosque, e o terceiro, o principal, formado de árvores geralmente de 5 a $6 \mathrm{~m}$ até 18 e 20 metros de altura, de troncos tortuosos, com predominância de madeiras duras".

\section{DESENVOLVIMENTO E EXPLORAÇÃO DE MADEIRA NATIVA DE CERRADO PARA EXPLORAÇÃO DE CARVÃO VEGETAL}

Para NETO (1991), o carvão vegetal é um subproduto da madeira, obtido através do processo denominado carbonização ${ }^{4}$, pelo qual ela é transformada em carvão e em outros produtos voláteis, pela ação do calor e em presença de quantidades controladas de oxigênio.

Dentre as várias utilidades do uso do carvão vegetal, o de maior importância atualmente é o seu emprego como redutor na siderurgia do ferro-gusa e do aço (LUENGO \& ENIMERICH, 1984; BRITO, 1990 e NETO, 1991).

O Estado de Minas Gerais apresenta condições ecológicas extremamente favoráveis ao cultivo de florestas homogêneas de Eucalipto em grande escala, e o uso do carvão dessa espécie é acentuado ainda mais pelo esgotamento progressivo da mata nativa (GOLFARI apud RESENDE, 1986).

Segundo GUILLAUMON (1989a), a destruição dos ecossistemas naturais, conforme estudo desenvolvido na região de Ribeirão Preto, SP, Brasil, demonstrou que o impacto do Reflorestamento Florestal passou desapercebido pela própria falta de consciência ecológica na época. Apesar das vantagens oferecidas, por um lado, propiciando a matéria prima que deixaria de ser retirada das áreas naturais, o Reflorestamento Florestal foi responsável pela destruição de 19,0\% do Cerrado existente na região, em 1962.

Para TIMONI, J. L. (Comunicação Pessoal), "o reflorestamento recebeu 
incentivos fiscais do Governo Federal, através das normas: Lei 5.106, de 02 de setembro de 1966; Decreto Lei 11.307, de 16 de janeiro de 1974; Decreto Lei 1.376, de 12 de dezembro de 1974; Portaria Conjunta do Ministérios da Agricultura e das Minas e Energia 934, de 30 de dezembro de 1976. Por não ser considerado floresta, o cerrado foi devastado por essa política de incentivos. A Portaria Conjunta 934/76 destinou recursos financeiros do Conselho Nacional do Petróleo (CNP) ao Instituto Brasileiro de Desenvolvimento Florestal (IBDF), para reduzir a dependência econômica do país em relação ao combustível fóssil, com a produção de lenha e carvão vegetal. O módulo estabelecido nessa norma (934/76) não poderia ser maior de 300 ha e menor de 10 ha, sendo assim, Minas Gerais foi o maior beneficiado dando grande impulso no reflorestamento".

\section{UTILIZAÇÃO DO CERRADO NO NOROESTE DO ESTADO DE MINAS GERAIS}

O Estado de Minas Gerais é privilegiado, por suas reservas de minério de ferro e por suas matas nativas, especialmente a de Cerrado. Tais fatores foram determinantes para a consolidação de indústrias siderúrgicas de grande porte. Essa vocação siderúrgica vem desde o Ciclo do Ouro (século XVIII), no entanto, como não interessava à Coroa Portuguesa sua emancipação econômica, foi determinado o fechamento de todas as fundições existentes. Somente a partir do século XIX foi novamente permitida essa atividade no Brasil, mas, em razão dos escassos recursos financeiros e técnicos e da falta de incentivos tarifários, sua consolidação só ocorreu no século XX.

Após a Primeira Guerra Mundial, a produção nacional de ferro e aço, que antes da guerra supria apenas $13 \%$ do mercado interno, passou a abastecer $43,5 \%$ desse mercado. Além disso, a crise de 1930 deu um novo impulso ao processo de substituição de importações, deslocando o centro dinâmico de economia do setor externo para o setor interno. A política econômica adotada pelo Governo Federal a partir de 1950 também veio favorecer o desenvolvimento da indústria siderúrgica em Minas Gerais.

Dentro dessa política econômica, a região Noroeste de Minas Gerais foi a que mais aproveitou e que mais se adaptou à produção ao consumo de carvão vegetal extraído do Cerrado.

O Noroeste de Minas Gerais corresponde à Macrorregião VI, localizando-se na porção setentrional do Estado de Minas Gerais. Engloba 54 Municípios, distribuídos em seis microrregiões, com superfície total de $161.190 \mathrm{Km}^{2}$, o que equivale a $27,46 \%$ da área do Estado. 
Essa Macrorregião tem 1.423.418 habitantes (Dados preliminares do Censo 1991), correspondente a 9\% da população do Estado. A principal fonte de renda e emprego é a agropecuária, que abrange $34 \%$ do PIB regional (13,8\% do total setorial do Estado) e emprega $59 \%$ da população ocupada na região. Destaca-se também a indústria extrativa mineral, que teve uma expansão significante entre 1975 e 1985, passando a deter 2,5\% do montante do valor da produção mineral do Estado. O percentual de pessoas que nunca freqüentou a escola ou que possui menos de um ano de estudo é de $47 \%$, ou seja, cerca de metade da população encontra-se excluída do processo educacional (MINAS GERAIS, 1994).

A utilização do carvão vegetal nas indústrias tornou-se uma atividade praticada no mundo todo e foi em razão desse fato e das possíveis conseqüências oriundas dessa prática, em contraste com a preservação e conservação do meio ambiente, que se fez necessária a utilização das normas jurídico-ambientais para se explorar racionalmente esse recurso natural, sem comprometer a sadia qualidade de vida e também o equilíbrio ecológico.

A exploração de espécies vegetais na produção de carvão vegetal nas siderurgias (maiores consumidoras atualmente) em nosso país data de muitos anos. PAULA apud MACHADO \& OLIVEIRA (1980), afirma que "a história da siderurgia a carvão vegetal no Brasil tem seu primórdio no século XVI, com Afonso Sardinha, que instala em Sorocaba, São Paulo, Brasil, a primeira fábrica de ferro no país". Afirmam o mesmo PEREIRA \& CARON (1967).

Nessa época, poucas eram as atenções relativas às atividades que poderiam causar danos ao meio ambiente. Essa mesma postura refletem as normas jurídicoambientais, ou seja, também não externam um interesse ambiental.

Segundo análises feitas em várias referências bibliográficas: BASTOS (1957); BARBOSA (1958); PEREIRA \& CARON (1967); PIMENTA (1967); BRAGA (1980); PIMENTA (1981); GOMES (1983); SALAZAR (1988), entre outras, a preocupação é restrita ao desenvolvimento econômico das siderurgias, e não com as questões envolvendo preservação e conservação ambiental.

Não é objeto desta pesquisa analisar as normas referentes ao carvão de pedra (hulha), porém é importante destacar seu início como ponto de referência. Segundo BAILLY (1943), a primeira norma a tratar de carvão foi a Lei 275, de 04 de julho de 1895, que facultou isenção de direitos de importação sobre maquinaria destinada à exploração e beneficiamento de carvão mineral nacional.

O carvão vegetal foi usado com maior intensidade no Brasil República, principalmente no início do século XX, com a substituição da hulha pela lenha, por causa de uma crise energética gerada pela guerra do Transvaal (iniciada em 1899), 
recentemente África do Sul (GUILLAUMON, 1989b), entre outros fatores já mencionados.

\section{EVOLUÇÃO DA LEGISLAÇÃO AMBIENTAL PARA EXPLORAÇÃO DE CARVÃO VEGETAL EM CERRADOS}

As análises mostram que o Governo Federal, com exceção dos incentivos, interveio pouco nas questões relativas às siderurgias que se utilizavam do carvão vegetal como combustível. A primeira norma encontrada foi o Decreto 12.944, de 30 de março de 1918.

Depois desse Decreto, muitos outros surgiram, trazendo favores às usinas siderúrgicas, e acelerando, assim, o processo de exploração das espécies vegetais para a produção de carvão vegetal. Entre esses está o Decreto 15.493, de 23 de maio de 1922, do Presidente Epitácio Pessoa.

O legislador, ao criar o Código Civil Brasileiro, promulgado em 1916, não fez previsão específica quanto à exploração de madeira para a produção de carvão vegetal e nem para outros problemas ambientais.

O mesmo ocorreu na elaboração do Decreto-lei 2.848, de 07 de dezembro de 1940 (Código Penal), e do Decreto-lei 3.688, de 03 de outubro de 1941 (Lei das Contravenções Penais), em que poucos artigos estão relacionados com a preservação e conservação do meio ambiente.

A primeira norma a regulamentar a exploração de madeira para a produção de carvão com enfoque ambiental foi o Decreto 23.793, de 23 de janeiro de 1934, publicado no Diário Oficial da União do dia 21 de março de 1935.

Trata-se do primeiro Código Florestal em nosso país, feito pelo Governo da República dos Estados Unidos do Brasil, durante a gestão do Presidente Getúlio Vargas.

Esse Código foi totalmente revogado pelo artigo 50 da Lei 4.771, de 15 de setembro de 1965, que criou o Código Florestal, o qual ainda está em vigor, mas com alguns de seus dispositivos revogados pela Lei 7.803, de 18 de julho de 1989, e pela Lei 9.605, de 12 de fevereiro de 1998.

Procurou-se nesta pesquisa reunir todas, ou quase todas, as normas federais e estaduais (do Estado de Minas Gerais) em vigência que disciplinam a exploração de madeira para a produção de carvão.

A fim de se ter uma compreensão global das normas vigentes que 
regulamentam a exploração de madeira para a produção de carvão vegetal, fez-se necessária a análise dos seguintes textos: Constituição da República Federativa do Brasil de 1988; Lei 4.771, de 15 de setembro de 1965 - Código Florestal; Lei 9.605, 12 de fevereiro de 1998 - Lei dos Crimes Ambientais; Lei Estadual 10.561, 27 de dezembro de 1991 - Lei Florestal de Minas Gerais.

\section{CONSIDERAÇÕES FINAIS}

Minas Gerais é, atualmente, o maior produtor e consumidor de carvão vegetal no Brasil, necessitando, por essa peculiaridade, de normas mais severas em defesa do meio ambiente.

O Cerrado, pelo que representa (alimentação, biodiversidade, ecologia, fisiologia, paisagem, entre outras), tem sido pouco preservado, quando analisadas as normas jurídico-ambientais.

$\mathrm{O}$ aproveitamento de áreas de Cerrado (agrícola pastoris, aproveitamento lenhoso para a produção de carvão e sua substituição pelos reflorestamentos, em destaque com espécies do gênero Eucalyptus) é, sem dúvida, o que contribui significativamente para o seu desmatamento.

Embora a exploração de espécies vegetais na produção de carvão nas siderúrgicas date, em nosso país, do século XVI, somente no início do século XX é que houve efetivamente normas jurídico-ambientais que regulamentassem a matéria, sendo a primeira o Decreto 12.944/18, que em seu conteúdo trazia incentivos às siderúrgicas, mas não abordava preocupações de ordem preservacionista e de conservação ambiental.

O Código Civil Brasileiro (1916), o Decreto-Lei 2.848/40 (Código Penal) e Decreto-Lei 3.688/41 (Lei das Contravenções Penais) não fizeram previsões específicas quanto à exploração de madeira para a produção de carvão vegetal, nem relativas ao Cerrado. Nessas normas, os dispositivos relacionados ao meio ambiente são esporádicos.

A primeira norma a regulamentar a exploração de madeira para a produção de carvão vegetal com preocupações ambientais foi o Decreto 23.793/34 (Primeiro Código Florestal).

As normas que regulamentam o carvão vegetal, em vigor no nível Federal e do Estado de Minas Gerais, são: Lei 4.771/65; Lei 5.870/73; Portaria - Ministério da Agricultura e Ministério de Minas e Energia 934/76; Instrução - Normativa IBDF 001/80; Decreto 88.207/83; Resolução CONAMA 001/86; Resolução CONAMA 011/86; Resolução CONAMA 011/88; Decreto 97.628/89; Decreto 97.635/89; Lei 7.997/90; Portaria IBAMA 1.938/90; Portaria Secretaria do Desenvolvimento Regional 140/90; 
Resolução CONAMA 013/90; Portaria IBAMA 732/91; Portaria Normativa IBAMA 083/91; Lei Minas Gerais 10.561/91; Portaria SEMAM/PR 139/92; Decreto Minas Gerais 33.944/92; Portaria Departamento de Comércio Exterior 028/92; Portaria IBAMA 44N/93; Convênio Ministério da Fazenda, Conselho Nacional de Política Fazendaria 083/93; Decreto 1.282/94; Portaria IBAMA 048/95; Resolução CONAMA 005/95; Portaria IBAMA 113/95; Portaria IBAMA 029/96; Convênio Ministério do Meio Ambiente, dos Recursos Hídricos e da Amazônia Legal, Fundação Pro - Cerrado 055/96; Instrução Normativa Ministério do Meio Ambiente, dos Recursos Hídricos e da Amazônia Legal 001/96; Portaria IBAMA 083/96; Portaria Secretaria de Comércio Exterior 018/96; Portaria Secretaria de Comércio Exterior 002/97; Portaria IBAMA 014N/97; Portaria IBAMA 017P/97; Portaria Minas Gerais IEF 021/97; Portaria IBAMA, Superintendência Estadual na Paraíba 002/97; Lei Minas Gerais 12.581/97; Portaria Minas Gerais IEF 053/97; Portaria Minas Gerais IEF 060/97; Ajuste complementar do Ministério das Relações Exteriores. Divisão de Atos Internacionais 000/97; Portaria Minas Gerais IEF 065/97; Portaria Minas Gerais IEF 078/97; Portaria Minas Gerais IEF 079/97; Resolução CONAMA 237/97; Lei 9.605/98; Portaria Minas Gerais IEF 049/98.

Não foi encontrada definição lato sensu do Cerrado em nossas normas; o que existem são definições stricto sensu de Cerrado e Cerradão (Portaria Normativa IBAMA 83/91 e Decreto de São Paulo 49.141/67). Esses tipos diferem entre si em suas definições, não contemplando o conceito ecológico de Floresta. É um problema que precisa ser resolvido para evitar o subjetivismo na aplicação de dispositivos ambientais.

Não há dispositivos explícitos, na Constituição Federal de 1988, que regulamentam o carvão vegetal ou o Cerrado. É inadmissível a omissão do termo Cerrado nessa carta, já que esse Bioma brasileiro é comparado sob o aspecto ambiental aos outros patrimônios nacionais do art. 225, $\S 4^{\mathrm{O}}$ da C.F (a Floresta Amazônica brasileira, a Mata Atlântica, a Serra do Mar, o Pantanal Mato-Grossense e a Zona Costeira).

Importante observação faz MACHADO (1999) ao comentar que "o conceito de patrimônio ambiental supera a noção de propriedade e aí está indicando a vigilância a ser mantida sobre esses bens no sentido de sua sustentabilidade, conservando-os para as atuais e futuras gerações (art. 225 "caput" CF). A Constituição Federal fez uma enunciação não exaustiva dos bens integrantes do patrimônio nacional, pois outros, como a vegetação do cerrado e a vegetação da caatinga, merecem também integrar o patrimônio nacional".

Embora existam normas infra-constitucionais no Estado de Minas Gerais, regulamentando o Cerrado, lamentavelmente esse Bioma foi também camuflado na Constituição Estadual de Minas Gerais na frase "e outras unidades de relevante interesse ecológico". Como é possível um Estado, em que a área do Cerrado representa 53\%, ou seja, mais da metade de seu território, não valorizar sua vegetação? 
As Constituições Federal e do Estado de Minas Gerais devem, por intermédio de emenda, explicitar o Cerrado para maior eficácia na sua preservação e conservação.

MACHADO (1998) orienta que "não é competência exclusiva da União legislar sobre todos os tipos de vegetação existentes no Brasil. Cabe, portanto, aos estados e municípios dispor sobre os outros recursos naturais, florísticos, que transcendem as florestas".

Com relação à Lei 4.771 (Código Florestal), muitos de seus dispositivos tratam de florestas, deixando lacunas quanto à aplicação a outros tipos de vegetação, dentre elas o Cerrado. A revisão desses dispositivos deve ser feita, a fim de tornar mais eficaz a aplicação dos mesmos. São alguns exemplos que devem ser revistos: art. $1^{\underline{0}}$, Parágrafo único; art. $3^{\mathrm{O}}$; $§ 1^{\mathrm{O}}$; $\operatorname{artigos} 6^{\mathrm{O}} ; 10 ; 11 ; 12$ e 14.

De acordo com o art. $16, \S 3^{0}$, da Lei $4.771 / 65$, único dispositivo que trata especificamente do Cerrado, é relevante que o meio ambiente deva ser preservado não apenas em conseqüência de percentuais, mas em virtude de sua interação entre biota e abiota, ou seja, daquilo que realmente representa em termos ambientais. O mínimo a ser preservado é $20 \%$, porém esse percentual deverá ser maior, dependendo das relações entre os seres vivos, a fim de não ferir o equilíbrio ambiental.

Mais especificamente, a substituição do Cerrado pelo reflorestamento homogêneo, sobretudo para a produção de carvão, constitui uma preservação dos tipos de vegetação, porém é essencial que o cultivo venha acompanhado de seu Plano de Manejo e do Estudo de Impacto Ambiental, a fim de reduzir, prevenir ou compensar o risco ao meio ambiente.

MACHADO (1993) defende que o estudo de impacto ambiental é procedimento administrativo de prevenção e de monitoramento dos danos ambientais; suas verificações e análises terminam por um juízo de valor, ou seja, uma avaliação favorável ou desfavorável do projeto.

Nota-se que há dispositivos, desde o decreto 12.944/18 (primeiro a tratar sobre carvão vegetal), para as empresas siderúrgicas manterem em cultivo as florestas necessárias ao seu suprimento de carvão vegetal. Porém, é preciso evoluir e adotar também o instrumento Estudo de Impacto Ambiental (EIA/RIMA).

$\mathrm{O}$ art. $2^{\mathrm{O}}$, Parágrafo único (Decreto 1.282/94), que regulamenta os artigos: 15, 19, 20 e 21 da Lei 4.771/65, é inconstitucional por descartar o EIA/RIMA (previsto no art. 225, $\S 1^{\underline{0}}$, inciso IV da Constituição Federal) quando feita a aprovação do Plano de Manejo pelo IBAMA. 
Deve se ressaltar que as atividades de reflorestamento homogêneo para abastecimento de empresas, com Plano de Manejo (destaque ao Eucalipto), podem ser lesivas ao meio ambiente, principalmente quando essas ocupam ou substituem formações vegetais nativas, entre elas o Cerrado.

Relevante dado mostra MACHADO (1999), em decisão proferida no Supremo Tribunal Federal pela inconstitucionalidade de dispositivo da Constituição do Estado de Santa Catarina, que houvera eliminado o estudo de impacto ambiental: "a atividade de florestamento ou reflorestamento, ao contrário do que se poderia supor, não pode deixar de ser tida como eventualmente lesiva ao meio ambiente, quando, por exemplo, implique substituir determinada espécie de flora nativa, com suas próprias especificidades, por outra, as mais das vezes sem identidade com o ecossistema local e escolhida apenas em função da utilidade econômica, com ruptura, portanto, do equilíbrio e da diversidade da flora local".

A Lei 12.596/95 (Lei Florestal de Goiás) não descarta a elaboração desse instrumento para fins de "carvoejamento", mesmo com o Plano de Manejo Sustentado ou Plano de exploração devidamente aprovado e licenciado pela autoridade de controle ambiental competente (art. $9^{\mathrm{O}}$ ). É interessante notar que essa norma, em seu art. 10, obriga a elaboração de EIA/RIMA acompanhado do Plano de Manejo Sustentado ou Plano de Exploração para algumas espécies, entre elas o Cerrado.

O art. 35 da Portaria IBAMA 029/96 ressalta a importância da aplicação do uso do Zoneamento Ecológico-Econômico. Este tem que ser feito na região Noroeste de Minas Gerais, acompanhado do EIA/RIMA, a fim de definir áreas de reflorestamento e áreas que deverão ser recuperadas por causa do forte desmatamento na região.

A Lei 9.605/98 trouxe novidades, entre elas, sem dúvida nenhuma, a mais importante foi admitir a responsabilidade da pessoa jurídica (pública e privada). Dentre os pontos negativos está o fato de haver um grande número de crimes que não incluem a modalidade culposa, conseqüentemente não admitindo a negligência, imprudência e imperícia. Uma lacuna é a ausência de qualificadora para os crimes cometidos em biomas brasileiros de relevância ecológica, como: Cerrado, Mata Atlântica, Floresta Amazônica, Pantanal, Caatinga, Mangue, entre outros.

Os artigos 45 e 46 dessa Lei revogaram o art. 26, alíneas h, i e q da Lei 4.771/65 (Código Florestal), com alterações que visam a proteger melhor o meio ambiente.

A Lei Estadual 10.561/91 (Lei Florestal de Minas Gerais) não traz em seu texto o bioma Cerrado expresso, porém seus artigos o protegem na sua utilização para a produção de carvão vegetal. 
É importante que outros Estados se preocupem com seus tipos de vegetação, visto que, em Minas Gerais, a Lei Florestal é bem restritiva para o uso de carvão vegetal, o que possibilita a procura desse produto fora desse Estado, especialmente nos seus vizinhos.

Assim como o convênio feito entre o Estado de Minas Gerais e a União, outras unidades também deveriam fazê-lo, a fim de tornar a preservação do meio ambiente mais efetiva e possibilitar uma maior aproximação das informações e fiscalizações com o público.

A educação ambiental (princípio constitucional) deve ser empregada na região, levando em consideração, além de outros aspectos, que $47 \%$ das pessoas nunca freqüentaram a escola ou possuem menos de um ano de estudos; além disso o índice de analfabetismo da população atinge $41 \%$.

O Direito Ambiental não poderá faltar nessa conscientização, porque a educação se concretiza a longo prazo, e agressões ocorrem no presente. Deverá fazer parte desse aprendizado a utilização dos instrumentos da tutela ambiental, entre eles a ação civil pública e a ação popular.

\section{REFERÊNCIAS}

Associação Brasileira de Carvão Vegetal - ABRACAVE. Jornal ABRACAVE. Belo Horizonte, MG. Ano VII, n.23, janeiro-março de 1998.

BAILly, G. A. Ministério da Agricultura - Coletânea da Legislação Brasileira desde a proclamação da república, 1943.

BARBOSA, F. A. Dom João VI e a Siderurgia no Brasil. Rio de Janeiro: Biblioteca do Exército, 1958.

BASTOS, H. A Conquista Siderúrgica no Brasil: crônica e interpretação econômica das empresas e indivíduos, nacionais e estrangeiros que participaram da exploração dos recursos minerais e do desenvolvimento nacional. São Paulo: Livraria Martins Editora, 1957.

BRAGA, C. A. P. Siderurgia no Brasil: história e análise da competividade internacional do setor nos anos 70. São Paulo. Dissertação (Mestrado em Economia) Faculdade de Economia e Administração, Universidade de São Paulo, 1980.

BRASIL. Constituição da República Federativa do Brasil (CF/88). Editora Revista dos Tribunais, 1996. 
BRITO, J. O. Princípio de Produção e Utilização de Carvão Vegetal de Madeira. Documento florestais, Piracicaba, p.1-19, 1990.

CAVALCANTI, T. B. Coleta e conservação de recursos genéticos no Brasil In: XLVII Congresso Nacional de Botânica, Nova Friburgo, RJ. Anais do XLVII Congresso Nacional de Botânica (Resumos). Rio de Janeiro: Sociedade Botânica do Brasil, p. 60-1, 1996.

Companhia Energética de Minas Gerais - CEMIG, Instituto de Desenvolvimento Industrial de Minas Gerais. Secretaria de Estado de Industria, Mineração e Comércio. Minas Gerais Cenários da Economia 1987/2005. Siderurgia, Belo Horizonte, n.7, 1988.

FERNANDES NETO, M. Estudo da cinética de secagem de leito de carvão vegetal para a siderurgia. Belo Horizonte, MG. Dissertação (Mestrado em Engenharia Metalúrgica e de Minas). Escola de Engenharia, Universidade Federal de Minas Gerais, 1993.

FERRI, M. G. In: IV Simpósio sobre Cerrado: bases para utilização agropecuária. Belo Horizonte: Itatiaia. São Paulo: Editora da Universidade de São Paulo, 1977.

Universidade de São Paulo, 1980.

GOMES, F. A. M. História da siderurgia no Brasil. Belo Horizonte: Itatiaia. São Paulo: Editora da Universidade de São Paulo, 1983.

GUILLAUMON, J. R. A crise energética e a destruição da cobertura vegetal natural na região de Ribeirão Preto, no período de 1962 a 1984. Anais do III Congresso Brasileiro de Defesa do Meio Ambiente. V.2, p.762-90, 1989a.

Mudança do polo econômico do nordeste para o sudeste, no Brasil, e a destruição da floresta - Mata Atlântica. Revista do Instituto Florestal. São Paulo, v.1, n.2, p.13-41, 1989b.

LOPES, A. S. Solos sob cerrado: características, propriedades e manejo. 2.ed. Piracicaba: Associação Brasileira para Pesquisa do Potássio e do Fosfato, 1984.

LUENGO, C. A. \& ENIMERICH, F. Fabricação de Carvão Vegetal. Série Tecnologia Agro-industrial. Governo do Estado de São Paulo - Secretaria da Industria e Comércio, 1984.

MACHADO, A. \& OLIVEIRA, G. F. Sistema de Energia na Siderurgia. Associação Brasileira de Metais, 1980. 
MACHADO, P. A. L. In: Anais do I Seminário sobre Direito Ambiental. Franca, 1993.

Editores, 1998.

Direito Ambiental Brasileiro. 7.ed. São Paulo: Editora Malheiros

O direito ambiental e a proteção das florestas no século XXI. In: Anais do $3^{\underline{O}}$ Congresso Internacional de Direito Ambiental: proteção jurídica das florestas tropicais. São Paulo: IMESP, v.1, p.7-14, 1999.

MINAS GERAIS. Assembléia Legislativa do Estado de Minas Gerais. Audiências Públicas Regionais: Macrorregião VI Noroeste. Minas Gerais, v.4, 1994.

NETO, E. T. Carvão Vegetal. Informativo Agropecuário. Belo Horizonte, v.15, n.168, p.57-9, 1991.

PEREIRA, A. O. \& CARON, M. L. E. Manual de Siderurgia: documentação técnica e informativa. Editora Assetec, 1967.

PIMENTA, D. J. Implantação da Grande Siderurgia em Minas Gerais - Belo Horizonte. Belo Horizonte: Imprensa da Universidade Federal de Minas Gerais, 1967.

1981.

A vale do Rio Doce e sua História. Belo Horizonte: Editora Veja,

RESENDE J. L. P et al. Localização econômica dos reflorestamentos com Eucalipto, para à produção de carvão vegetal em Minas Gerais. Revista Árvore. V.10: p.60-81, 1986.

SALAZAR, J. M. O esconderijo do sol: a história da Fazenda Ipanema desde a primeira forja do Brasil até a real fábrica de ferro. 2.ed. Brasília: Editora Brasília, Ministério da Agricultura, 1988.

SANTILI, J. A proteção aos direitos intelectuais coletivos das comunidades indígenas brasileiras. Revista Centro de Estudos Judiciários. Brasília, DF, v.1, n.3, p.46-53, 1997.

SILVA, J. A. Frutas nativas dos cerrados. Brasília, DF: EMBRAPA/CPPAC, 1994.

3 A definição de meio ambiente está na Lei $6.938 / 81$, de 31 de agosto de 1981 , art. $3^{0}$, I: - meio ambiente é o conjunto de condições, leis, influências e interações de ordem física, química e biológica, que permite, abriga e rege a vida em todas as suas formas. 